\title{
Computer Aided Lighting Requirement Analysis and Design for a Health Care Facility
}

\author{
Tanuja S \\ Dept. of CSE \\ Manipal Institute of Technology \\ Manipal University
}

\author{
Shailesh K R \\ Dept. of $E$ \& $E$ \\ Manipal Institute of Technology \\ Manipal University
}

\begin{abstract}
The healthcare sector of today has very precise requirement with regard to interior lighting. To fulfill these needs, international standards which specify the strict requirement for each health care facility have come up. Hospital lighting is in particular complex because of the sensitive nature of various patients as well as requirement of high performance from its employees. Hence this makes for a challenging task for designing a lighting scheme for a hospital. Hospital lighting standards have been well documented by IESNA and its Indian counterpart-National Lighting Code 2010. This work aims at providing healthcare lighting of an international standard in a new health care facility namely of a super specialty hospital. Widespread usage of computer simulation as well as International standards like ANSI RP-29-06, have been rigorously followed and implemented. Thus the aim of this work is creating an optimum system where not only the lighting is optimum but the energy consumption of the said facility is also optimized.
\end{abstract}

\section{Keywords}

Health care lighting, Day lighting, Artificial lighting, Hospital lighting, patient care lighting

\section{INTRODUCTION}

Designing lighting for healthcare is always a challenging task. In this case the healthcare facility being attempted is not yet constructed. This increases the challenge of the project yet creates immense possibilities to start designing from scratch instead of just trying to improve an existing facility. Thus this project is an attempt to create a world-class facility with regard to lighting. Lighting design is incomplete without incorporating day-lighting. Unfortunately major challenges have been thrown up with regard to this parameter. The AutoCAD layouts revealed that for the new OPD day-lighting was not used for interior illumination.

Day-lighting has been shown to affect the patients in a positive manner as controlled daylight is softer than artificial lighting and provides higher illumination in the room in general [1]. Several studies have shown that natural light in hospitals reduces energy costs and improves physiological and psychological states of both staff and patients [2]. Coolwhite fluorescent lighting is banned for hospital lighting in certain European countries [3]. The spatial quality obtained from windows is of psychotherapeutic quality by providing outside views and day light [4]. Circadian rhythms of Alzheimer's patients can be improved by exposing the patients to bright illumination during the day time, which makes them less prone to depression $[5,6]$.

Aging eyes must be considered in all common areas of medical facilities. People over age 65 constitute more than 50 percent of the volunteer force helping in medical facilities. They are the heaviest users of health service and require proper lighting with better contrast and higher task luminance $[7,8]$. Good quality lighting will lessen the duty for caregivers [9]. Outpatient services are expanding. Thus outpatient procedures often require the same quality and quantity of illumination found in an acute care setting [10]. Also many patient operations are now carried out in special ambulatory operating rooms with associated recovery rooms. The motivation of this project comes from the apathy commonly seen while lighting hospitals in India. It is seen that even major hospitals do the bare minimum or less when it comes to proper lighting techniques. Hence this project can be seen as an attempt to improve lighting practices in hospitals. One of the important objectives of this project was to create an ideally lit hospital which is also energy efficient.

\section{TECHNICAL BACKGROUND}

It has been proved that proper lighting has a positive effect on the health and well-being of recovering people [11]. Sunlight is the primary source of natural light and the job of lighting engineers and scientists very recently have been to mimic the effect of natural sunlight. Saying this is easier said than done as the quality of sunlight can be achieved only by full spectrum lighting at a fraction of the intensity of natural sunlight.

\subsection{Areas in Hospitals which require lighting}

\subsubsection{Public lighting for corridors, stairways and} lobby area

Corridor lighting requires special attention as it has to provide adequate illumination on pathways, staircases and sign boards. It's important that transversely mounted fixtures should be avoided in this region as it may cause visual disturbance to patients moving in wheel chairs and trolleys. Continuous lines of luminaires positioned along one side of the corridor are preferred compared to fixtures along the centerline [12].

\subsubsection{Patient Ward Lighting}

Hospital ward lighting is an important area of the hospital. Where possible there is a considerable daylight contribution. During the daytime and visiting hours ward lighting should be bright. There must be no flicker. All fluorescent lighting should be based on the use of high frequency electronic ballasts. Also individual patient lighting must be easy to operate, even by patients with limited mobility. Depending upon the type of ward, there may be a need for patient examination light at each bed. But individual lighting for each patient must ensure that the patient in the neighboring beds is 
not disturbed by the glare. Daytime lighting near the windows can be up to 25000 lux. Bedside lighting should not be less than 30-50 lux and not less than 100 lux in the central space between beds according to the lighting guide on hospitals by CIBS 1979a.

\subsubsection{Diagnostic and Treatment Spaces}

Typically dominated by planning criteria, such as circulation distance, proximity, and adjacency requirements, operating rooms and procedure rooms are often located at the core of a deep floor plate with no access to views and daylight. Breaking up the D\&T area requires careful planning, but locating these spaces at the building perimeter for day lighting and views is feasible without surrendering flexibility according to AEDG for large hospitals ASHRAE IESNA.

\subsubsection{Operation Theaters and Clean Rooms}

Operation theaters need both localized (high task illuminance) and general lighting (background illuminance for staff to carry out supplementary task). In order to ensure continuity of illuminance during power failure adequate arrangement for emergency lighting should be provided. The luminaires used in clean rooms must be sealed and easily maintainable under sterile environment. Lighting should provide stress free visual environment helping the staff to carry out their tasks over long periods of time. Low wattage sealed recessed corrosion resistant FTL luminaires are installed in these areas paying adequate attention to reduce shadows.

\subsubsection{Staff Areas (Exam Rooms, Nurse Stations, and Offices)}

Locating staff spaces on the building perimeter is essential to staff performance, and a design strategy that facilitates efforts to conserve energy by reducing electric light and cooling loads. The staff areas have multitude of uses like being reception or administrative area. Lighting scheme should create a hospitable environment that ensures that the station is visually important.

\section{OBJECTIVE OF THE WORK}

Most of the projects studied as a part of literature survey were mainly project where re-design of lighting scheme is done. The work undertaken in this project involves work on requirement analysis, design and implementation.

This project is aimed at providing energy efficient and effective lighting solutions for a super specialty hospital which conforms to the highest level of patient and employee comfort according to international standards.

\subsection{Proposed Solution}

The propose solution is explained in Fig. 1 below.

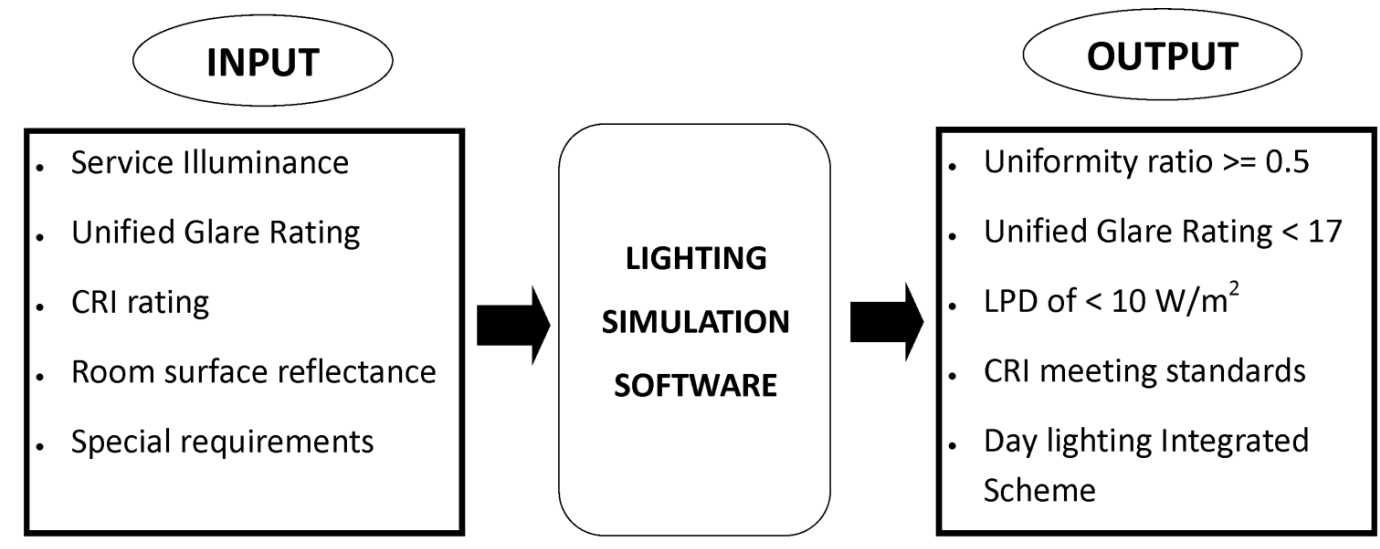

Fig 1 : Block Diagram representing the inputs required to simulate the project and the proposed / desired output

Input to the flow chart shows the room requirements both quality and quantity of illumination. Output of the flow chart show the expectations from design in terms of energy efficiency, patient comfort and aesthetics are achieved.

The methodology consists of mainly computer simulations. One of the important task was estimating the lighting requirement analysis for different areas of the hospital as per both IESNA RP-29-06 and NLC 2010.

Computer simulations was done considering special requirements for each room, for instance Classrooms should have a service illuminance of 300lux, Glare Index of less than 16 , CRI $>75$ with direct-indirect luminaires. Scanner rooms were challenging as they shouldn't have ferrous based electromagnetic component lighting hence incandescence or LED lighting fixtures are to be used. During design stage there were two possibilities, choosing between best design and optimum design. Best design is one in which energy efficiency or cost factor is not considered but only the best possible illumination. In optimum design takes into account all factors including energy efficiency and cost of luminaires. To realize optimum design it is often necessary to create the best design first.

\subsection{Design constraints}

Civil design of certain sections like OPD was finalized during the project work hence design given by this project is with an assumption that the unfinished areas would appear as assumed. Existing civil design does not give due consideration to day lighting. Day lighting is marginal; hence reliance on artificial lighting is more. Exactly same luminaire may not be used. Simulation result may not be same as practical result hence a degree of overdesign has to be tolerated. 


\section{PROJECT IMPLEMENTATION}

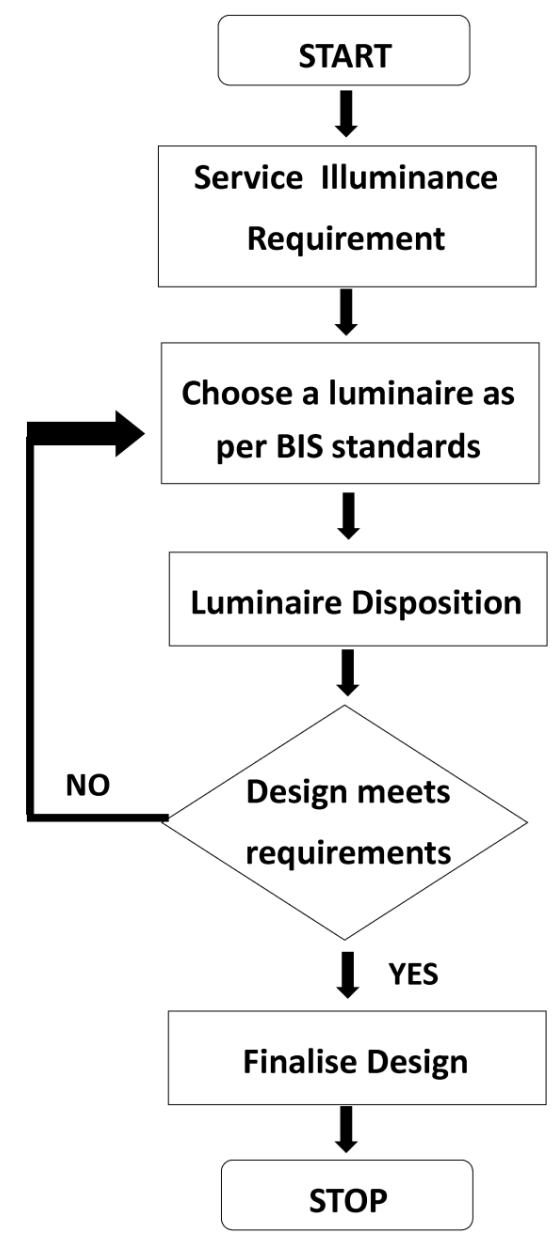

Fig 2 : Flowchart of project implementation

\section{RESULTS ANALYSIS}

\subsection{Project Area 1: Classroom 1 (Capacity 40)}

\subsubsection{Area 1 requirements}

- Preferably fluorescent lighting will be used

- Illumination requirement 300 lux minimum

- $\quad$ Glare rating to be less than 16 .

- Power density to be less than 10.5 watts $/ \mathrm{m}^{2}$

Students in a classroom spend their day looking at the desk; have frequent interaction with the class teacher or instructor and class mates. Students also stare at the teaching surface like white board. The eyes will be strained because of the contrasts between teaching surfaces and reflectance of the surrounding walls and ceiling. By using lighting fixtures that use both direct and indirect lighting, a uniform illuminance distribution can be obtained in the classroom.

Vertical illuminance should be at least one third of the horizontal illuminance on the work surface; this will ensure that both the instructor and teaching aids are sufficiently lit. Even though this can be achieved with overhead lighting, dedicated wall lighting can add an extra dimension.
Table 1 : Installation Data for Classroom Type 1

\begin{tabular}{|c|c|}
\hline Area $\left(\mathrm{m}^{2}\right)$ & 48 \\
\hline Number of Luminaires & 6 \\
\hline Luminaire Type & $\begin{array}{l}\text { i.) OSRAM Surface mounted } \\
\text { luminaires / T8 lamps / } \\
\text { EUROPLEX (X 4) } \\
\text { ii.) OSRAM LED Fixtures / } \\
\text { LEDVANCE® DOWNLIGHT } \\
\text { XL (X 2) }\end{array}$ \\
\hline Luminaire Efficacy & $\begin{array}{l}\text { i.) } 42.12 \quad \mathrm{~lm} / \mathrm{W} \quad(81.9 \% \mathrm{dl} \\
\text { 18.1\% } \\
\text { ii.) } 60.71 \mathrm{~lm} / \mathrm{W}(100.0 \% \mathrm{dl})\end{array}$ \\
\hline Lumen Output & $\begin{array}{l}\text { i.) } 6400 \mathrm{~lm} / \text { fixture } \times 4 \\
\text { ii.) } 1700 \mathrm{~lm} / \text { fixture } \times 2 \\
\text { Total Lumen Output }=29000 \\
\text { lumens }\end{array}$ \\
\hline Wattage & $\begin{array}{l}\text { i.) } 110 \mathrm{~W} \times 4=440 \mathrm{~W} \\
\text { ii.) } 28 \mathrm{~W} \times 2=56 \mathrm{~W} \\
\text { Total Power }=496 \mathrm{~W}\end{array}$ \\
\hline Daylight Factor & 0 \\
\hline Average Lux & $343 \operatorname{lux}$ \\
\hline $\mathrm{LPD}(\mathrm{W} / \mathrm{m} 2)$ & $10.48(<10.5 \mathrm{~W} / \mathrm{m} 2)$ \\
\hline $\begin{array}{l}\text { Lux Distribution } \\
\text { (Emin / Em) }\end{array}$ & 0.38 \\
\hline Glare Index & $<5.1$ \\
\hline
\end{tabular}

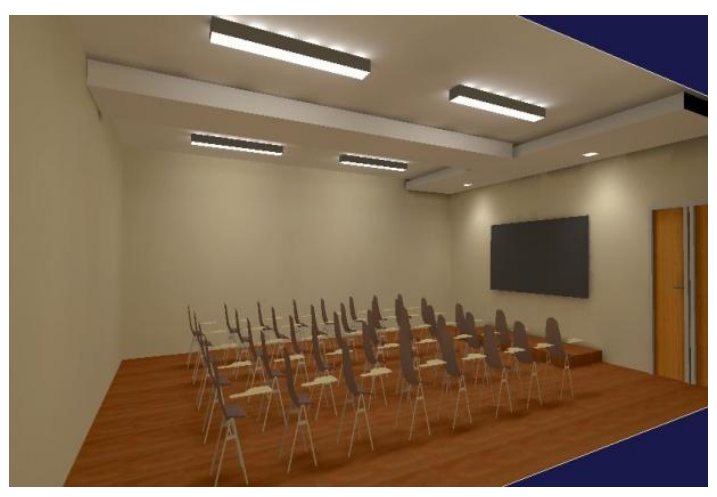

Fig 3 : Lighting simulation of classroom of Type 1

The hospital is also used as a teaching hospital with classrooms in the OPD itself; classroom lighting occupies a major part in the design. The recommended classroom illuminance depends on the tasks to be performed. Suspended direct-indirect luminaires provide down lighting and reflected light from the ceiling. Well-designed indirect lighting systems provide low-brightness, shadow-free illumination. Many school classrooms, however, have low ceilings that necessitate ceiling-mounted luminaires. In the designed class room ceiling mounted direct-indirect lighting has been used to provide a shadow-free lighting area. OSRAM luminaires have been used and near the black-board LED down-lighters along with stepped ceiling have been used to light the board in a glare-free way.

\subsection{Project Area 2: Consultation Room}

\subsubsection{Area lighting requirements}

- $\quad$ Illuminance requirement- upto 400 lux for office space and upto 350 lux for bed space

- $\quad$ Glare rating should be less than 17 
- Bedside lighting to be provided at a height of $160-170 \mathrm{~cm}$ from the floor

Table 2 : Installation Data for consultation rooms

\begin{tabular}{|c|c|}
\hline Area $\left(\mathrm{m}^{2}\right)$ & 18 \\
\hline Number of Luminaires & $2+1$ \\
\hline Luminaire Type & $\begin{array}{l}\text { i.) Cooper Lighting - } \\
\text { VYHP236Z ceiling mounted } \\
\text { luminaire VARSITY } \\
\text { HOSPITAL (x 2) } \\
\text { ii.) OSRAM - 4008321931511 } \\
\text { Indoor - Batten luminaires/T5 } \\
\text { batten/OSRAM MINI5® ECO } \\
\text { (x 2) }\end{array}$ \\
\hline Luminaire Efficacy & $\begin{array}{l}\text { i.) } 71.28 \mathrm{~lm} / \mathrm{W}(86.4 \% \mathrm{dl} \\
13.6 \% \mathrm{ul}) \\
\text { ii.) } 41.85 \mathrm{~lm} / \mathrm{W}(70.5 \% \mathrm{dl} \\
\text { 29.5\% } \\
\end{array}$ \\
\hline Lumen Output & $\begin{array}{l}\text { i.) } 6700 \mathrm{~lm} / \text { fixture x } 2 \\
\text { ii.) } 430 \mathrm{~lm} / \text { fixture x } 1 \\
\text { Total Lumen Output = } 13830 \\
\text { lumens }\end{array}$ \\
\hline Wattage & $\begin{array}{l}\text { i.) } 36 \mathrm{~W} \times 4=144 \mathrm{~W} \\
\text { ii.) } 7.5 \mathrm{~W} \times 1=7.5 \mathrm{~W} \\
\text { Total Power }=151.5 \mathrm{~W}\end{array}$ \\
\hline Daylight Factor & 4 \\
\hline Average Lux & 387 lux \\
\hline $\mathrm{LPD}\left(\mathrm{W} / \mathrm{m}^{2}\right)$ & $8.5\left(<10.5 \mathrm{~W} / \mathrm{m}^{2}\right)$ \\
\hline $\begin{array}{l}\text { Lux Distribution } \\
\text { (Emin / Em) }\end{array}$ & 0.42 \\
\hline Glare Index & $<17$ \\
\hline
\end{tabular}

The consultation room serves both as an office as well as an examination room. Hence sufficient task lighting has to be given for ordinary office work and low powered halogen examination light with a reflector can be given to provide 400 lux for ordinary examination over the bed-head.

It is worth-while to note that the OPD functions mostly during the day and early evening. In simulations it's found that it is almost never necessary to switch on the luminaires during the day time and in the evening only one luminaire would suffice for general lighting or only examination lighting required for examination purposes. Hence energy can be saved here.

It's important that the lighting in consultation room aids communication between patient and doctor. Both doctor and patient need to focus - so that nothing that needs to be told or reported is forgotten. Good visual comfort helps in promoting mental alertness. Indirect lighting combined with accent lighting is pleasant for the patient and most favorable for the doctor.

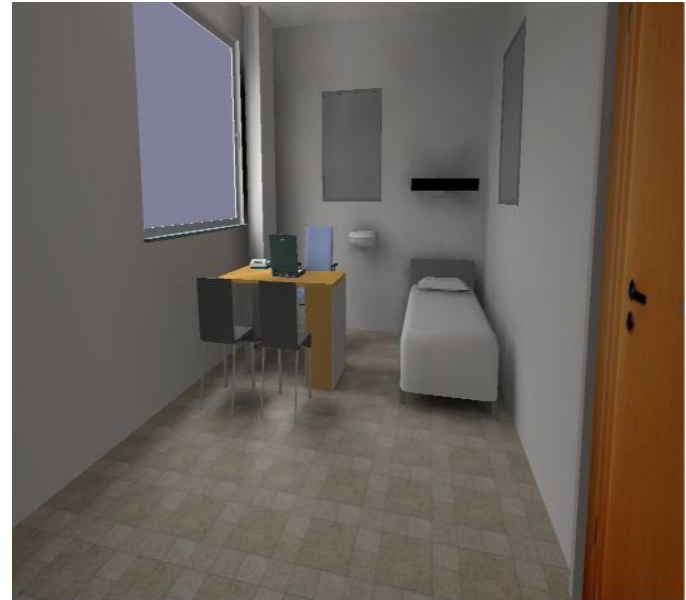

Fig 4: Day lighting in consultation room.

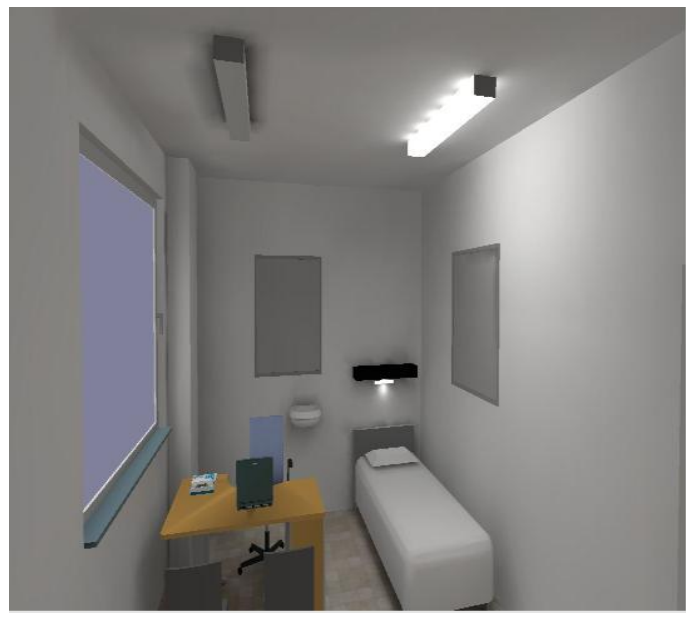

Figure 5 : Simulation at 6:15 pm which shows that when daylight is reduced acceptable norms are still followed if only a single luminaire is used for general lighting and an OSRAM ecolux is used with a reflector for examination lighting

\subsection{Project Area 3: Surgery Department}

The Surgery department is one of the major simulated areas and consists of the following subareas. Note that the Medicine department on the second floor is identical to this area and hence can be lighted in a similar fashion.

a) Nurses Station: The nurses' station according to IESNA lighting handbook should have multi-level lighting. The task lighting should be arranged so that it supplements the general illumination of the station. Computer and monitoring VDTs should be positioned or screened to eliminate glare at normal viewing angles.

b) Common Patient Area : It can be considered as an office lighting space hence recessed lighting can be used but since patients are to be seen here, CRI requirements of the lighting are high ( as high as 90).

c.) Examination Rooms: The lighting for examining patients in their rooms should be of a color quality that does not distort skin or tissue color, of a directionality to permit careful inspection of surfaces and cavities, and shadow-less. When curtains are used to isolate a patient, others in the room are protected from the examining lamp; however, whether fixed 
or portable, the examination lighting should be confined to the bed area and provide adequate lighting over a circular area 0.6 $\mathrm{m}(2 \mathrm{ft})$ in diameter.

d.) Consultation Room: HOD's Chamber being a consultation room has already been discussed above.

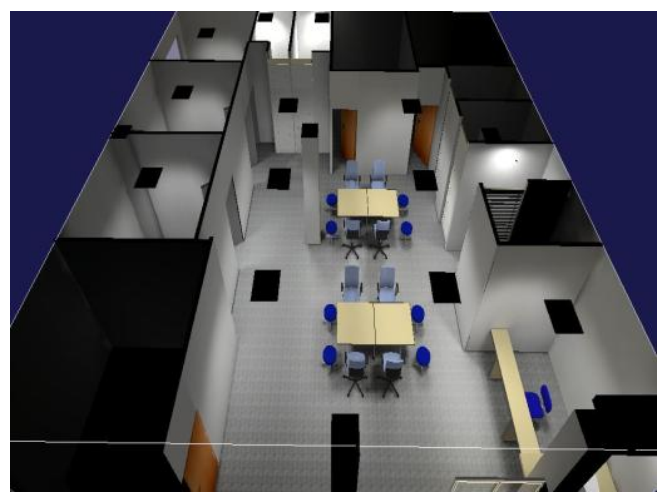

Fig 6 : Lighting simulation of surgery department

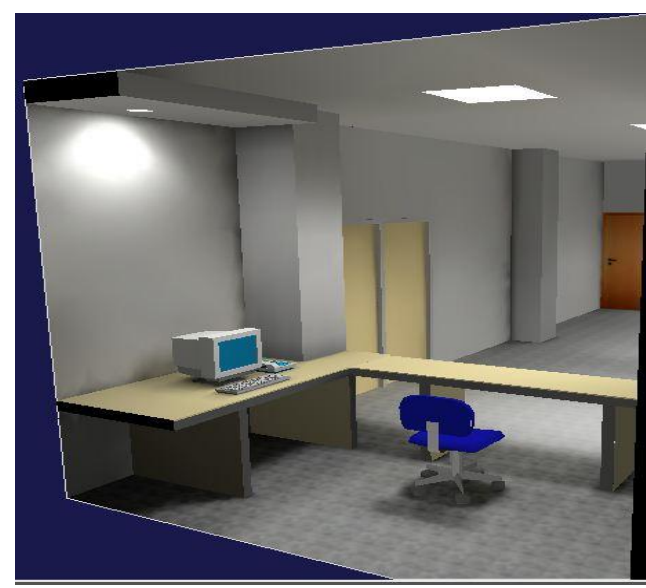

Fig 7 : Multilevel lighting in the nurses' station. LED lighting has been used and the light is not directly below the computer to avoid glare

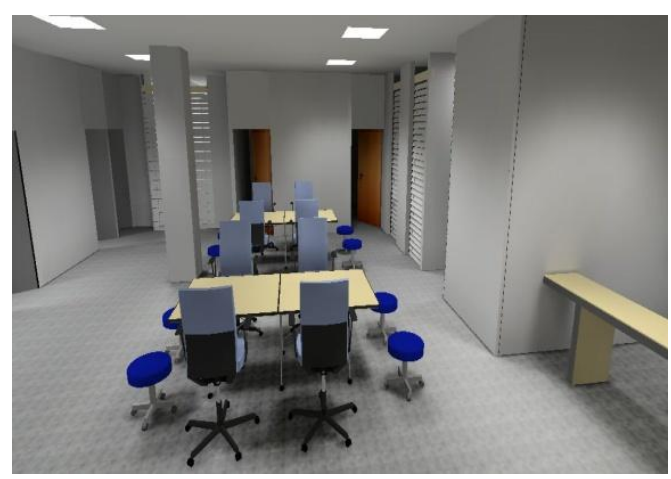

Fig 8 : Illumination in common patient's area

Lighting in common patients area is provided by recessed louver type luminaire which distribute light uniformly.
Table 3 Lighting installation data of surgery department

\begin{tabular}{|c|c|}
\hline Area $\left(\mathrm{m}^{2}\right)$ & 165 \\
\hline Number of Luminaires & 14 installed and simulated \\
\hline Luminaire Type & $\begin{array}{l}\text { i.) OSRAM 4050737038506 } \\
\text { Luminaires / Indoor - } \\
\text { Recessed luminaires / T5 } \\
\text { lamps / SITECO LOUVRE } \\
\text { ii.) OSRAM - 4008321931412 } \\
\text { Luminaires / Indoor - Batten } \\
\text { luminaires / T5 batten / } \\
\text { OSRAM MINI5® ECO } \\
\text { iii.) OSRAM - } \\
\text { 4008321966094 LED systems, } \\
\text { Light Engines and Modules / } \\
\text { Illumination / PrevaLED Core } \\
\text { iv.) OSRAM - } \\
\text { 4008321968784 Luminaires / } \\
\text { Indoor - OSRAM LED } \\
\text { Fixtures / LEDVANCE® } \\
\text { DOWNLIGHT } \\
\text { v.) Cooper Lighting - } \\
\text { MCRA240Z recessed } \\
\text { luminaire COOPER - } \\
\text { MODUCELL }\end{array}$ \\
\hline Luminaire Efficacy & $\begin{array}{l}\text { i.) } 66.07 \mathrm{~lm} / \mathrm{W} \\
\text { ii.) } 57.79 \quad \mathrm{~lm} / \mathrm{W} \quad(70.5 \% \mathrm{dl} \\
\text { 29.5\% } \mathrm{ul}) \\
\text { iii.) } 75 \mathrm{~lm} / \mathrm{W} \\
\text { iv.) } 49.22 \mathrm{~lm} / \mathrm{W} \\
\text { v.) } 41.92 \mathrm{~lm} / \mathrm{W}\end{array}$ \\
\hline Lumen Output & $\begin{array}{l}\text { i.) } 3600 \mathrm{~lm} / \text { fixture x } 2 \\
\text { ii.) } 950 \mathrm{~lm} / \text { fixture x } 1 \\
\text { iii.) } 2100 \mathrm{~lm} / \text { fixture } \\
\text { iv.) } 1000 \mathrm{~lm} / \text { fixture } \\
\text { v.) } 7000 \mathrm{~lm} / \text { fixture } \\
\text { Total Lumen Output = } 55950 \\
\text { lumens }\end{array}$ \\
\hline Wattage & $\begin{array}{l}\text { i.) } 36 \mathrm{~W} \mathrm{x} 4=144 \mathrm{~W} \\
\text { ii.) } 7.5 \mathrm{~W} \mathrm{x} 1=7.5 \mathrm{~W} \\
\text { Total Power }=151.5 \mathrm{~W}\end{array}$ \\
\hline Daylight Factor & 4 \\
\hline Average Lux & 173 lux (for lighted areas) \\
\hline LPD (W/m2) & $4.49(<10.5 \mathrm{~W} / \mathrm{m} 2)$ \\
\hline $\begin{array}{l}\text { Lux Distribution ( Emin } \\
\text { / Em) }\end{array}$ & 0.58 \\
\hline Glare Index & 15 \\
\hline
\end{tabular}

\subsection{Project Area 4 : Floor Waiting Hall and Corridor}

Corridor being a public hospital area has very stringent rules due to the part it plays in safety during patient transits or general point of movement through a hospital. Older eyes adapt less quickly to differences in light level, and an even light distribution within a space makes rooms and hallways easier to navigate. Scalloped lighting effects on corridor walls, or alternating high and low illumination levels within the space, produce visual confusion that can make these areas more difficult to negotiate. Overhead lighting reflected by a polished floor often produces discomfort or disability glares. Highly reflective floors should be avoided. Glossy surfaces, especially near large-area windows, can also create severe glare problems. Floor surfaces should not contain strong or highly contrasting patterns, which could be misinterpreted as shadows, changes in height, or as objects on the floor. Shadows are to be avoided its best to go for direct-indirect lighting. The NLC defines corridor lighting to be 100-150 lux 
depending upon the ward lighting so that patients do not get disoriented when they come into the corridor.

Table 4: Lighting installation data for corridor and waiting hall

\begin{tabular}{|l|l|}
\hline Area $\left(\mathrm{m}^{2}\right)$ & 213 \\
\hline Number of Luminaires & 9 \\
\hline Luminaire Type & $\begin{array}{l}\text { i.) OSRAM - 4039806616135 } \\
\text { Luminaires / Indoor - Surface } \\
\text { mounted luminaires/T8 } \\
\text { lamps/EUROPLEX (x 9) }\end{array}$ \\
\hline Luminaire Efficacy & $\begin{array}{l}\text { i.) } 46.74 \mathrm{~lm} / \mathrm{W} \text { ( 72.6\%dl } \\
27.4 \% \text { ul) }\end{array}$ \\
\hline Lumen Output & $\begin{array}{l}\text { i.) } 3200 \mathrm{~lm} / \text { fixture x 9 } \\
\text { Total Lumen Output }=48000 \\
\text { lumens }\end{array}$ \\
\hline Wattage & $\begin{array}{l}\text { i.) } 56 \mathrm{~W} \text { x 9 = 504 W } \\
\text { Total Power }=840 \mathrm{~W}\end{array}$ \\
\hline Daylight Factor & 0 \\
\hline Average Lux & 105 lux \\
\hline LPD (W/m2) & $3.95(<10.5 \mathrm{~W} / \mathrm{m} 2)$ \\
\hline $\begin{array}{l}\text { Lux Distribution ( Emin / } \\
\text { Em) }\end{array}$ & 0.34 \\
\hline Glare Index & $15(<16)$ \\
\hline
\end{tabular}

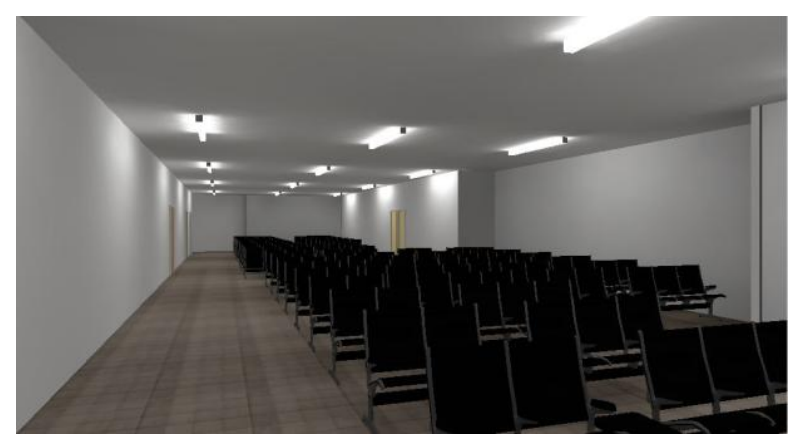

Fig 9: Lighting simulation of corridor and waiting hall

\subsection{Project Area 5: Scanner Rooms}

Various types of scanning machines are used for diagnostic purposes. The patient is usually prone on a table that either moves under or into the scanning device, or the device may move over the patient. Light in these rooms is usually indirect so that the light source is not in the patient's direct line of sight. Many scanning rooms have valance or perimeter lighting with both upward and downward components.

General lighting controlled by a dimming system in the control and scanning rooms provides low illuminance during treatments and high illuminance for equipment maintenance and setup. MRI utilizes powerful magnetic fields in the diagnostic process. Therefore, nonferrous, direct-currentpowered incandescent luminaires or LED lighting should be used in the scanning room, to eliminate the effects of the magnetic fields on the lighting system and also to reduce the interference of magnetic objects in the diagnostic image produced during the scanning process.
Table 5 : Lighting installation data for scanner rooms

\begin{tabular}{|l|l|}
\hline Area (m2) & 25 \\
\hline Number of Luminaires & $4+4$ \\
\hline Luminaire Type & $\begin{array}{l}\text { i.) OSRAM - 4008321963376 } \\
\text { LED systems, Light Engines } \\
\text { and Modules / Illumination / } \\
\text { PrevaLED Core (x 4) } \\
\text { ii.) OSRAM - 4008321968876 } \\
\text { Luminaires / Indoor - OSRAM } \\
\text { LED Fixtures / LEDVANCE® } \\
\text { DOWNLIGHT XL (x 4) }\end{array}$ \\
\hline Luminaire Efficacy & $\begin{array}{l}\text { i.) 55.26 lm/W } \\
\text { ii.) 60.71 lm/W }\end{array}$ \\
\hline Lumen Output & $\begin{array}{l}\text { i.) 2100 lm/fixture x 4 } \\
\text { ii.) 1700 lm/fixture x 4 } \\
\text { Total Lumen Output = 15200 } \\
\text { lumens }\end{array}$ \\
\hline Wattage & Total Power = 264 W \\
\hline Daylight Factor & 0 \\
\hline Average Lux & $\begin{array}{l}325 \text { lux during operation, 540 } \\
\text { lux for general service }\end{array}$ \\
\hline LPD (W/m2) & $\begin{array}{l}6.05 \text { during operation(<10.5 } \\
\text { W/m2), 10.56 during general } \\
\text { service }\end{array}$ \\
\hline $\begin{array}{l}\text { Lux Distribution ( Emin / } \\
\text { Em) }\end{array}$ & $\begin{array}{l}\text { during general service } \\
10.5 \text { during operation }\end{array}$ \\
\hline Glare Index & \\
\hline
\end{tabular}

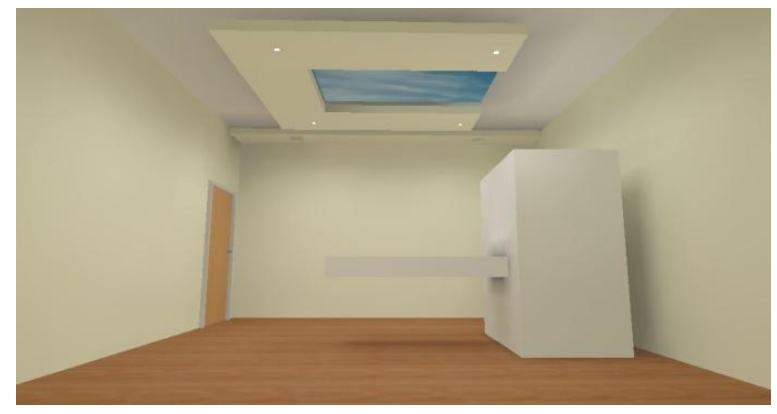

Fig 10: Lighting in scanner rooms

Lighting in scanner rooms is dimmed during normal operating conditions lighting to a level of 300-330 lux. Glare control is priorities as harsh lighting can make patients nervous.LED lights with non magnetic ballasts are used. Scanner room lighting requires special attention. Illuminance levels of general lighting needs to be reduced for information and images shown on Computer screens. Reflection and glare free images should be displayed on monitors used in scanner rooms. There should be a balanced luminance distribution around the monitor, key board and the surroundings; this will facilitate the job of the doctor. 


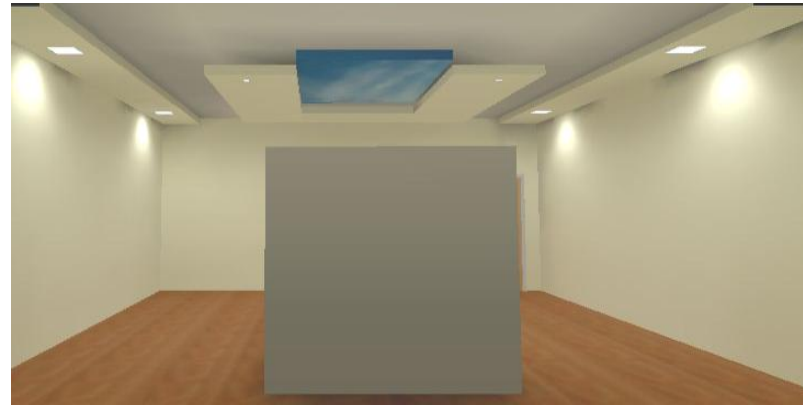

Figure 11 : Another view of lighting simulation in the scanner room

\section{CONCLUSION}

From this preliminary computer simulations and requirement analysis we can conclude the following points:

- Achieving energy efficiency was one of the major requirements of the project. The LPD target for the project was $10.5 \mathrm{~W} / \mathrm{m}^{2}$ for each room. The design was successfully in achieving the targeted LPDs in most cases much better than target.

- Patient comfort was the second priority of the project. It can be said that this priority was achieved with partial success. As IESNA and NLC standards have been vigorously followed patient comfort will be positively achieved.

- In the report analysis it can be seen that UGR ratings are achieved as per requirement and so are the CRI ratings.

- Realistic rendering of lighting schemes is achieved. Material specification given by the engineers has been as closely followed as possible, and where these specifications were failing the designers took the liberty of changing them. LED lighting was recommended wherever possible. Although expensive initially, their long life compensates the cost.

- One of the major inherent weaknesses in the architectural design was the lack of day-lighting. Day lighting has been neglected to a very great extent which results in the reliance on artificial lighting and which in turn reduce the overall efficiency of the building.

While designing ideal conditions were assumed. This does not account for variable change, for instance, MF (Maintenance Factor) is assumed to be high throughout which may not be the case. Simulation has been done for a vacant room without furniture and occupants. Hence designers have slightly overdesigned a few areas which will compensate when people (patient and staff) are present.

\subsection{Future Scope}

At present field-work has not been undertaken. The next step is to undertake field-work in some of the newer installations in the Old OPD to check for the more efficient lighting. Hence the project can be extended for doing comparative analysis of existing and proposed schemes. Future scope also includes the use of sensors. Sensors can help improve safety and energy efficiency. This can be made into a hardware project. For example: a sensor which can detect the age of the patient and adjust the lighting of the room accordingly.

\section{REFERENCES}

[1] L. Edwards and P. Torcellini, "A Literature Review of the Effects of Natural Light on Building Occupants", National Renewable Energy Laboratory, 2002

[2] Verderber S, "Human Response to Daylighting in the Therapeutic Environment", Proceedings of International Day lighting Conference,1983,pg. 415

[3] Walker M, "The Power of Color", Online: http://www.vitalight.com/articles/walker.htm, 1998.

[4] Vischer, J.C, "The Effects of Day lighting on Occupant Behavior in Buildings: New Directions for Research", International Daylighting Conference Proceedings II, 1986, pp.419-429.

[5] Lighting Futures, "Light, Sight and Photobiology", Vol. 2, No.3,1998

[6] Perron D, "Creating an Alzheimer's Facility: Promoting independence and sustaining dignity with accurate design", Assisted Living Success, 2001

[7] Jones B, "Lighting and the Elderly", Environdesign Journal,2001

[8] Veitch J A, "Lighting Quality Contributions from Biopsychological Processes", Journal of the Illuminating Engineering Society, 2001, pp. 2-16.

[9] Dilouie C, "New Research Offers Possibilities of Light as a Nighttime Stimulant", Reprinted from Architectural Lighting, 1997

[10] Franta G and Anstead K, "Daylighting Offers Great Opportunities", Window \& Door Specifier-Design Lab,1994,pp. 40-43

[11] McHugh J, Burns P J and Hittle D C, "The Energy Impact of Daylighting”, ASHRAE Journal, 1998, pp. 3135 .

[12] Thorn Lighting, "Applications in Focus Lighting for Healthcare", 2013 